\title{
Review of Developments in Electronic, Clinical Data Collection, and Documentation Systems over the Last Decade - Are We Ready for Big Data in Routine Health Care?
}

\author{
Kerstin A. Kessel ${ }^{1,2 *}$ and Stephanie E. Combs ${ }^{1,2}$ \\ ${ }^{1}$ Department of Radiation Oncology, Technische Universität München, Munich, Germany, ${ }^{2}$ Institute of Innovative \\ Radiotherapy (iRT), Helmholtz Zentrum München, Neuherberg, Germany
}

OPEN ACCESS

Edited by:

Issam El Naqa,

McGill University, Canada

Reviewed by:

Valdir Carlos Colussi,

University Hospitals Case

Medical Center, USA

Derek Merck,

Rhode Island Hospital, USA

*Correspondence:

Kerstin A. Kessel

kerstin.kessel@tum.de

Specialty section:

This article was submitted to

Radiation Oncology,

a section of the journal

Frontiers in Oncology

Received: 13 January 2016 Accepted: 18 March 2016

Published: 30 March 2016

Citation:

Kessel KA and Combs SE (2016)

Review of Developments in Electronic, Clinical Data Collection,

and Documentation Systems over the Last Decade - Are We Ready for

Big Data in Routine Health Care?

Front. Oncol. 6:75.

doi: 10.3389/fonc.2016.00075
Recently, information availability has become more elaborate and widespread, and treatment decisions are based on a multitude of factors, including imaging, molecular or pathological markers, surgical results, and patient's preference. In this context, the term "Big Data" evolved also in health care. The "hype" is heavily discussed in literature. In interdisciplinary medical specialties, such as radiation oncology, not only heterogeneous and voluminous amount of data must be evaluated but also spread in different styles across various information systems. Exactly this problem is also referred to in many ongoing discussions about Big Data - the "three V's": volume, velocity, and variety. We reviewed 895 articles extracted from the NCBI databases about current developments in electronic clinical data management systems and their further analysis or postprocessing procedures. Few articles show first ideas and ways to immediately make use of collected data, particularly imaging data. Many developments can be noticed in the field of clinical trial or analysis documentation, mobile devices for documentation, and genomics research. Using Big Data to advance medical research is definitely on the rise. Health care is perhaps the most comprehensive, important, and economically viable field of application.

Keywords: data collection system, electronic data capture, documentation system, data management system, Big Data

\section{INTRODUCTION}

In modern medicine, large data volumes, including imaging, treatment documentation, and followup information, are collected within the hospital or practice environment. Even in the age of intelligent information systems, doctors, nurses, and other health workers are faced with the difficulty of sharing data within the medical facility $(1,2)$. Thus, several groups have been working on various approaches solving this important task (3-5).

Recently, information availability has become more elaborate and widespread, and treatment decisions are based on a multitude of factors, including imaging, molecular or pathological markers, surgical results, and patient's preference. In the past, paper-based documentation was the standard, which has been partially digitalized over the years, often leading to parallel worlds of 
documentation in one institution. As disease management steps into the era of modern personalized medicine (6), including various quantitative data, information becomes a strong focus, thus involving the active contribution of multiple medical specialties. Established structures to gather all significant data are therefore of high importance for reaching the best clinical performance and enhancing interdisciplinary and clinical research. Ultimately, this leads to the improvement, adaptation, and redevelopment of health-care concepts.

In interdisciplinary medical disciplines, not only heterogeneous and voluminous data must be evaluated but also spread across various information systems within several involved departments in a large variety of documentation styles $(7,8)$. Furthermore, in highly image intensive specialties, such as radiation oncology or radiology, diagnostic and therapeutic data acquisitions are acquired throughout the course of treatment and during followup. Clinicians and researchers need assistance in reusing the terabytes of invaluable information collected routinely into separate information systems (9). They hold hidden treasures (10). Exactly this concept is also referred to in many ongoing discussions about Big Data - the "three V's": volume, velocity, and variety (10). One could even add variability (inconsistency in data) and veracity (differences in data quality) as two more V's equally important characteristics, especially in a medical context. To avoid double documentation, loss or mix-up of data, and to provide a fast and reliable basis to collect all relevant data, interconnected information systems have been developed (5).

The achievement of building systems merging all these specifications is a challenging task from both a technical and non-technical point of view. The focus must lie in providing flexibility and increasing performance for the future. This is associated with a vendor independent (6) and Integrating the Healthcare Enterprise (IHE) complying concept that strictly obeys given specifications for patient confidentiality and security mechanisms. Innovative methods and ideas are gaining ground in the field, which will be investigated by this analysis. We want to take a step back and perform a broad review of the developments in electronic clinical data management systems and the standards for data storage of the last decade, with special respect to the further processing of the collected data.

\section{METHODS}

Published data on the subject of clinical documentation and management systems within the last decade were searched for in all NCBI databases with specific inclusion/exclusion criteria. The terms for search were " $((($ data collection system[Title/Abstract] $)$ OR electronic data capture[Title/Abstract]) OR documentation system[Title/Abstract]) OR data management system[Title/ Abstract]) AND ('2004/06/30'[Date - Publication]: '2014/06/30' [Date - Publication])." We explicitly did not include the term "Big Data" to characterize the developments solely on clinical documentation of the last decade. The search delivered 895 hits. Subsequently, the following inclusion criteria were applied to the references: English or German language, topic of research, and medical specialty. Based on these criteria, 34 articles not written in English or German language were excluded from the analysis. We reviewed the articles and excluded further five articles, as they were not referring to any use or implementation of a data management system.

The review process was done by both authors. First, we reviewed the title and abstract of all articles. We looked at the topic of each paper and classified them in use or implementation of data management systems; comparison of new systems with a previous standard; or recommendations about system implementation and discussions about issues after system introduction.

Documentation and data management systems are used in many medical and biological specialties. It was not always possible to clearly determine the classification of an article. Particularly, interdisciplinary research activities across multiple disciplines and reveal a clear overlap between multiple topics. We obtained the main discipline of each paper and listed all those containing at least 15 articles. Furthermore, many articles contained insufficient information in the abstract some even had none. In this case, we read the whole paper to determine the topic of research and grouped each paper in a medical or biological specialty. In the final step, we carefully examined all papers containing descriptions about system implementation to find postprocessing ideas and concepts.

A Papers 3 library (Mekentosj B.V., Amsterdam, Netherlands) was used to collect and organize the references. Figure 1 illustrates the overall review methodology.

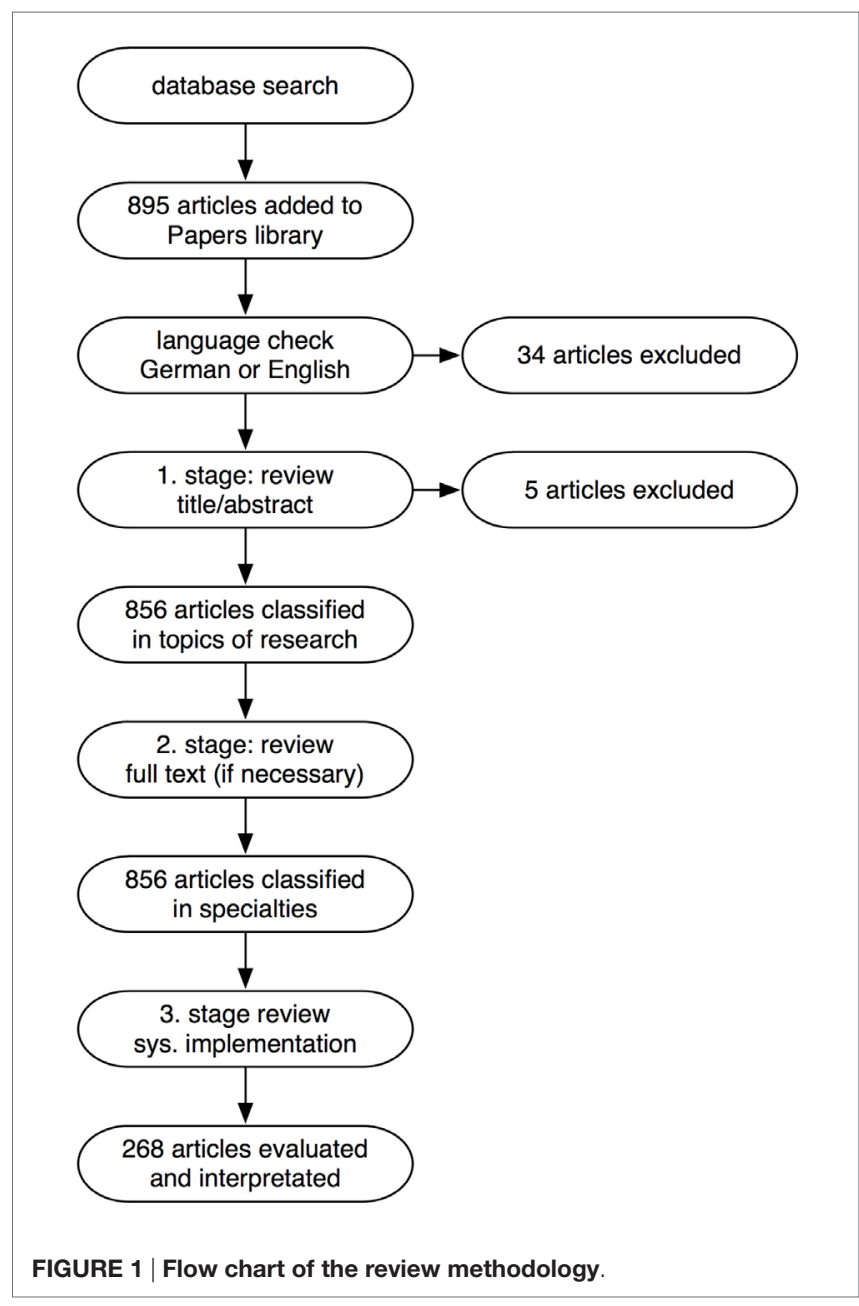




\section{RESULTS}

Classification of articles into medical specialty and topic of research can be found in Tables $\mathbf{1}$ and 2, respectively.

\section{System Implementation}

About one-third of all articles $(n=268)$ specifically discuss the development of a data collection system/database (as opposed to those referring to a system as a tool), and the results of implementing a data management system into the clinical environment.

Most of the developed systems provide data utilization through query, analytic, export, and reporting tools. These report and export functionalities are used with regard to statistical analyses, for example, by importing the data into a statistic software, such as SPSS, for further calculations. Only five of those articles discuss first ideas and ways to immediately make subsequent use of collected data, particularly imaging data $(11,12)$, for advanced analysis or postprocessing procedures beyond basic statistic analysis. Table 3 summarizes the work of these five research groups. The general criticism of the articles is that details about the implementations are vague and no general concept is presented, which could be transferred into another setting.

With the Big Data challenge, emerging data mining is a buzzword becoming more and more widespread, which is also

\section{TABLE 1 | Specialty of the articles.}

\begin{tabular}{lc}
\hline Specialty & No. of articles \\
\hline Biology & 96 \\
Chronic disease management & 67 \\
Emergency and critical care medicine & 63 \\
Epidemiology & 24 \\
Health technology and medical informatics & 95 \\
Neuroscience & 17 \\
Nursing & 109 \\
Oncology & 41 \\
Palliative medicine & 19 \\
Pediatrics & 22 \\
Pharmacy & 19 \\
Psychiatry and psychotherapy & 27 \\
Public health & 37 \\
Surgery & 31 \\
Teaching & 17 \\
Other & 172 \\
Not assigned & 39 \\
\hline
\end{tabular}

TABLE 2 | Topics of articles.

\begin{tabular}{lc}
\hline Topic & No. of articles \\
\hline System use & 469 \\
- For clinical trial or analysis & 370 \\
- For clinical routine & 99 \\
System implementation & 268 \\
System comparisons with paper-based standard or other systems & 24 \\
System review, recommendations, and issues & 95 \\
Not assigned & 39 \\
\hline
\end{tabular}

reflected in recent articles in documentation and management systems (13-15).

\section{System Use}

More than half of all articles $(n=469)$ mention the use of an electronic system, especially in clinical trial or analysis documentation (370/469). This trend is attributable to the many advantages, such as accessibility, backup, or central storage as opposed to paper-based documentation (5).

Many developments include mobile devices for documentation and making information available whenever wherever through web-based or app solutions. Especially in the field of nursing or chronic disease management, patients' self-monitoring of health information takes place on web-based health platforms or apps (21-24). The use of mobile technologies in health care is also a trend in developing countries, where no global IT infrastructures but cellular networks are available (25-28).

\section{System Comparison and Review}

Comparisons (24/469) and reviews (95/469) of systems are equally indicative: electronic data capture and documentation systems help in data gathering problems but lead to new problems on a technical and financial level.

Figure 2 illustrates the research topics distributed over the specialties. Clearly, documentation supported by electronic systems in the areas of chronic disease management, nursing, and emergency medicine is successfully in use. These documentation systems maintain the daily recording of patient and treatment data, whereas in surgery, public health, epidemiology, and

TABLE 3 | Articles with further processing strategies and approaches of collected data.

\begin{tabular}{|c|c|c|}
\hline Reference & Year & Summary \\
\hline Brown et al. (16) & 2007 & $\begin{array}{l}\text { Analysis tools connected to data management } \\
\text { system for quantitative image analysis in } \\
\text { metastatic lung cancer patients; automatic nodule } \\
\text { detection and segmentation for CAD evaluation; } \\
\text { communication standards used: DICOM }\end{array}$ \\
\hline Carey et al. (17) & 2012 & $\begin{array}{l}\text { Analysis tools used on imaging files stored in } \\
\text { database in lung cancer patients; manual image } \\
\text { analysis; no communication standardization } \\
\text { mentioned }\end{array}$ \\
\hline Haak et al. $(11,18)$ & 2014 & $\begin{array}{l}\text { Analysis tools connected to EDC system } \\
\text { for automatic image and biosignal analysis; } \\
\text { communication standards used: web services, } \\
\text { ODM, SOAP, SFTP, HTTP }\end{array}$ \\
\hline $\begin{array}{l}\text { Kessel et al. (12, } \\
\text { 19) }\end{array}$ & 2012 & $\begin{array}{l}\text { Analysis tools connected to documentation } \\
\text { database via SQL interface; semiautomatic CT } \\
\text { image registration and segmentation of pancreatic } \\
\text { cancer patients, as well as dose calculation of } \\
\text { radiation plans; communication standards used: } \\
\text { HL7, DICOM, https }\end{array}$ \\
\hline Ozyurt et al. (20) & 2010 & $\begin{array}{l}\text { Analysis tools used on local copies of neuroimaging } \\
\text { data after query and download from the data } \\
\text { management system; results are transferred back } \\
\text { via web services; communication standards used: } \\
\text { web services, SOAP, DICOM, https }\end{array}$ \\
\hline
\end{tabular}

$C A D$, computer-aided diagnosis; DICOM, digital imaging and communications in medicine; EDC, electronic data capture; HL7, health level 7; SQL, structured query language; ODM, object data model; SOAP, simple object access protocol. 


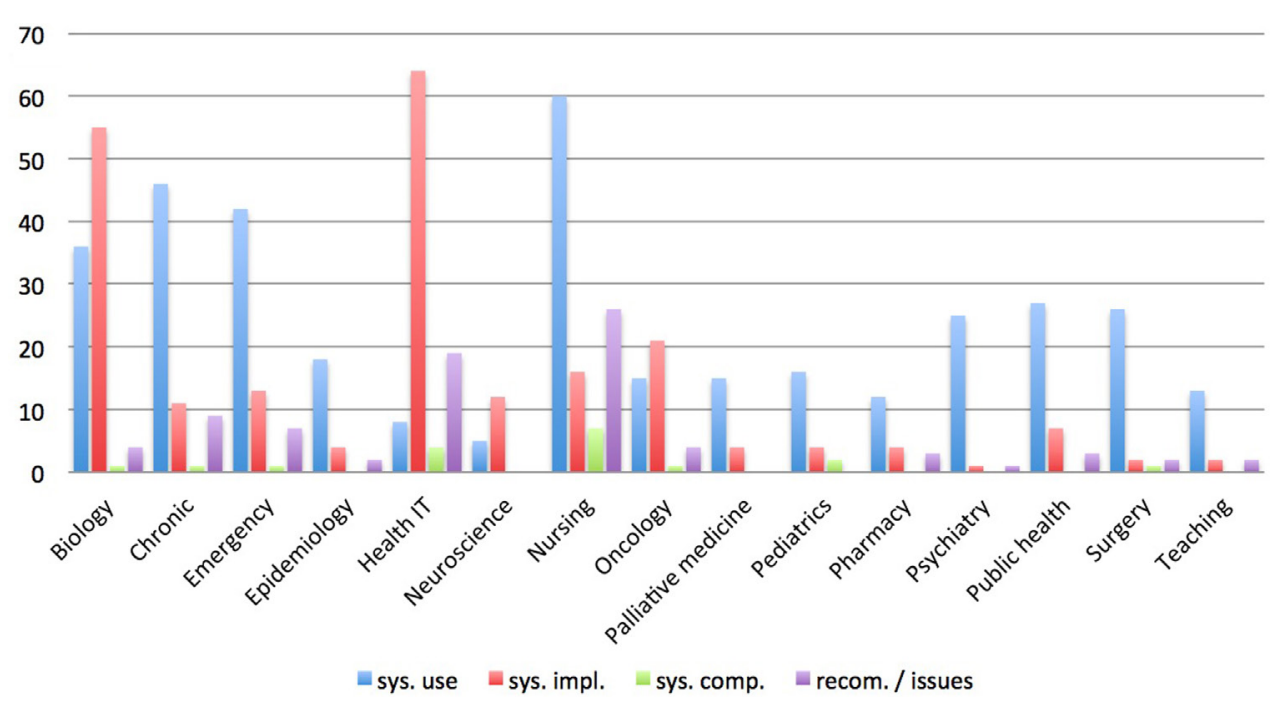

FIGURE 2 | Diagram showing the research topics distributed over the specialties.

pharmacy documentation systems are mostly recording clinical trials and evaluations.

Naturally, the sector of health technology and medical informatics is most advanced in the development and implementation of documentation and management systems. Of equal relevance are the advances in biological genomics science. Here, numerous calculations are executed and massive amounts of data arise; hence, systemic data storage and management are essential. Many groups present their research environment, and an increasing interest in developing tools for further analysis can be noticed $(13,29,30)$.

Recent advances and developments are currently made in the interdisciplinary disciplines, such as radiology, radiation oncology, and neuroscience $(4,12,17,20,31-33)$. These involve various types of data, such as multimodal imaging, laboratory, and treatment data, which need to be correlated to analyze research questions and extract new information.

\section{DISCUSSION}

The Big Data challenge occupies all fields of science and economy. Just recently major companies, such as Google with Google Fit and Apple with HealthKit, started their platforms announcing "a health revolution" (34).

A lot of information increasingly accumulates. Automatic analyses are on the rise to manage this amount of data. Since literature on this topic is widespread and of varying quality, derives from several disciplines and misses detail to some extent, the aim of the present review is to summarize and classify reports on systems and implementation approaches to cope with the data challenge in medicine and to provide a basis for subsequent implementation strategies.

The tendency of having two (documentation) systems in a clinical facility is clearly visible $(35,36)$. On the one side is a clinical system, which can be an electronic health record (EHR) or hospital information system (HIS) in various designs used for routine and everyday patient and treatment documentation, on the other side, research systems are becoming established for scientific purposes (such as clinical trials, evaluations, and research data pool). Both data management systems go hand in hand, and structures are developed to share information, such as treatment and lab parameters, follow-up data and imaging, etc., between both and to avoid redundant data.

It is not the lack of technology or tools that keep "the health revolution" from coming, but the lack of expertise, specifications, and concepts (4). One of the most common weaknesses found is the lack of standardization. Most researchers create an individual in-house solution without considering communication standards, such as DICOM, HL7, https, and html (37). These solutions work only in their own environment and are tailored to meet their requirements. This might be necessary up to a certain level, as already stated that there is no "one-size-fits-all" solution for documentation of clinical trials, research data, or patient data per se (38). However, one must consider the further use of data, data sharing over time, and analysis procedures, which depend on standardized infrastructures and must comply with concepts of anonymization, liability, and data security. The importance lies in an interoperable approach - no "island solution." Only coherent IT solutions bring sustainable and profound improvement of processes. It is up to us to enforce little known and little-established standards in health-care developments (3).

It may still be an idealized vision to be able to answer research questions in a medical department with a single mouse click. Many groups are working exactly with this aim in mind, but to date, only partial success can be reported. Based on the technology available, this seems to become possible in the future. The connection of analysis tools to a data management system and building an analysis pipeline is essential for this and the next logical step. However, an evaluation process depends highly on data resources. An effective data management is essential for any 
useful data analyses. Only with electronically captured, complete and high-quality data from the very beginning, conversion of data into new information delivers meaningful results.

In health-care environments, some scenarios have been demonstrated how automatic processing can be combined with manual interactions $(5,19)$. The concept to transfer this idea to an automatic workflow must consist mainly of two facts: (a) use current standards and work compliant to these standards and (b) build a central data pool that contains the "Big Data." The idea can be summarized as ASER: acquire, store, exchange, and reuse of data.

Various techniques are currently underway, with simple object access protocol (SOAP) or web services only two mentioned, that provide functionality to attain that concept of combining analysis tools and execute them consecutively for an automatic analysis procedure $(11,39)$. Web services or services, in general, are characterized by their interoperability and their wide distribution even in the mobile world. They have the advantages to coordinate multiple tasks and at the same time be able to cope with large, heterogeneous data sets and high computation intensity. Handling heterogeneous, voluminous data sets is a fundamental requirement for working in an interdisciplinary environment, as already mentioned. Computer-aided diagnostics (CAD) applications could enable large amounts of data to be extracted for analyses as well.

Probably, more papers could be found with a database search focusing on analysis and postprocessing of data; however, the aim of the present work was to identify and review the current status of the connection of documentation and data management system in combination of subsequent analysis strategies.

The concept we propose is to take the next step and invest and build an intelligent infrastructure and craft complex algorithms. It should include a library of sophisticated analysis services/tools to be plugged together as needed for a specific research question, possibly in a way that it is usable for researchers with no or little IT knowledge to "make use of the Big Data" in health care. This way collaborative translational research will be effective and capable of handling all sorts of data. It already becomes its own profession to manage and coordinate Big Data having not only strong communication skills in an interdisciplinary environment but

\section{REFERENCES}

1. Onbay TU, Kantarc1 A. Design and implementation of a distributed teleradiaography system: DIPACS. Comput Methods Programs Biomed (2011) 104:235-42. doi:10.1016/j.cmpb.2011.05.006

2. Huang HK. PACS and Imaging Informatics. Hoboken, NJ: John Wiley \& Sons (2010).

3. Skripcak T, Belka C, Bosch W, Brink C, Brunner T, Budach V, et al. Creating a data exchange strategy for radiotherapy research: towards federated databases and anonymised public datasets. Radiother Oncol (2014) 113:303-9. doi:10.1016/j.radonc.2014.10.001

4. Poline J-B, Breeze JL, Ghosh S, Gorgolewski K, Halchenko YO, Hanke M, et al. Data sharing in neuroimaging research. Front Neuroinform (2012) 6:9. doi:10.3389/fninf.2012.00009

5. Kessel KA, Bohn C, Engelmann U, Oetzel D, Bougatf N, Bendl R, et al. Fiveyear experience with setup and implementation of an integrated database system for clinical documentation and research. Comput Methods Programs Biomed (2014) 114:206-17. doi:10.1016/j.cmpb.2014.02.002

6. Maitland ML, Schilsky RL. Clinical trials in the era of personalized oncology. CA Cancer J Clin (2011) 61:365-81. doi:10.3322/caac.20135 also multiple abilities such as knowledge about clinical processes, workflows, and underlying infrastructures as well as a strong scientific interest and IT background.

The visionary is already thinking about putting the Big Data into the cloud while most hospitals are still fighting with standard conform infrastructure. Still simple IT problems cause great difficulties in clinical routine, especially in large centers. However, the idea of Big Data analyses is tempting and would help us move personalized medicine forward. In summary, to answer our initial question, "Are we ready for Big Data in routine heath care?" we would answer no. Previously, we have reported on the details of our survey about data management in routine healthcare environments (37). Only 7\% stated that they are starting to develop solutions to cope with Big Data.

\section{Study Limitations}

The research aim was to give a broad overview of the current status developments in electronic, clinical data collection, and documentation system. No specific aspects of data management systems are discussed.

\section{CONCLUSION}

Using Big Data to advance medical research is now on the rise. Health care is perhaps the most comprehensive, important, and economically viable field of application. Adding meaning and context to Big Data can be achieved by investing in infrastructure and software and combining procedures to an analysis workflow. However, until now less experience is available on how to develop research questions that can be answered by such an infrastructure, and how to transfer the results into routine patient care. How soon are we able to incorporate it into decision-making?

\section{AUTHOR CONTRIBUTIONS}

KK performed the database search and review, drafted, and wrote the manuscript. SC revised the articles review as a second author. All authors read and approved the final manuscript.

7. Mandal A, Asthana AK, Aggarwal LM. Development of an electronic radiation oncology patient information management system. J Cancer Res Ther (2008) 4:178. doi:10.4103/0973-1482.43342

8. Law M, Liu B, Chan LW. DICOM-RT-based electronic patient record information system for radiation therapy. Radiographics (2009) 29:961-72. doi:10.1148/rg.294085073

9. Ohmann C, Kuchinke W. Future developments of medical informatics from the viewpoint of networked clinical research. Interoperability and integration. Methods Inf Med (2009) 48:45-54.

10. Prokosch H-U, Ganslandt T. Perspectives for medical informatics. Methods Inf Med (2009) 48(1):38-44. doi:10.3414/ME9132

11. Haak D, Samsel C, Gehlen J, Jonas S, Deserno TM. Simplifying electronic data capture in clinical trials: workflow embedded image and biosignal file integration and analysis via web services. J Digit Imaging (2014) 27:571-80. doi:10.1007/s10278-014-9694-Z

12. Kessel KA, Habermehl D, Bohn C, Jäger A, Floca RO, Zhang L, et al. Database supported electronic retrospective analyses in radiation oncology. Strahlenther Onkol (2012) 188:1119-24. doi:10.1007/s00066-012-0214-0

13. Zimmerman MD, Grabowski M, Domagalski MJ, MacLean EM, Chruszcz M, Minor W. Data management in the modern structural biology and 
biomedical research environment. Methods Mol Biol (2014) 1140:1-25. doi:10.1007/978-1-4939-0354-2_1

14. Tepas JJ. Data mining: childhood injury control and beyond. J Trauma (2009) 67:S108-10. doi:10.1097/TA.0b013e3181af0ad7

15. Bowman I, Joshi SH, Van Horn JD. Visual systems for interactive exploration and mining of large-scale neuroimaging data archives. Front Neuroinform (2012) 6:11. doi:10.3389/fninf.2012.00011

16. Brown MS, Shah SK, Pais RC, Lee YZ, McNitt-Gray MF, Goldin JG, et al. Database design and implementation for quantitative image analysis research. IEEE Trans Inf Technol Biomed (2005) 9:99-108. doi:10.1109/ TITB.2004.837854

17. Carey GB, Kazantsev S, Surati M, Rolle CE, Kanteti A, Sadiq A, et al. Utilisation of a thoracic oncology database to capture radiological and pathological images for evaluation of response to chemotherapy in patients with malignant pleural mesothelioma. BMJ Open (2012) 2:e001620. doi:10.1136/ bmjopen-2012-001620

18. Deserno TM, Haak D, Samsel C, Gehlen J, Kabino K. Integrating image management and analysis into OpenClinica using web services. In: Law MY, Boonn WW, editors. Proc. SPIE Medical Imaging, Vol. 8674. Orlando: SPIE (2013). p. 86740F.

19. Kessel KA, Habermehl D, Jäger A, Floca RO, Zhang L, Bendl R, et al. Development and validation of automatic tools for interactive recurrence analysis in radiation therapy: optimization of treatment algorithms for locally advanced pancreatic cancer. Radiat Oncol (2013) 8:138. doi:10.1186/1748717X-8-138

20. Ozyurt IB, Keator DB, Wei D, Fennema-Notestine C, Pease KR, Bockholt J, et al. Federated web-accessible clinical data management within an extensible neuroimaging database. Neuroinformatics (2010) 8:231-49. doi:10.1007/ s12021-010-9078-6

21. Whiting SW, Dixon MR. Creating an iPhone application for collecting continuous ABC data. J Appl Behav Anal (2012) 45:643-56. doi:10.1901/ jaba.2012.45-643

22. Bellamy N, Wilson C, Hendrikz J, Whitehouse SL, Patel B, Dennison S, et al. Osteoarthritis index delivered by mobile phone (m-WOMAC) is valid, reliable, and responsive. JClin Epidemiol (2011) 64:182-90. doi:10.1016/j. jclinepi.2010.03.013

23. Lee D-Y, Bae S, Song JH, Yi BK, Kim IK. Improving chronic disease management with mobile health platform. Conf Proc IEEE Eng Med Biol Soc (2013) 2013:2275-8. doi:10.1109/EMBC.2013.6609991

24. Pavluck A, Chu B, Flueckiger RM, Ottesen E. Electronic data capture tools for global health programs: evolution of LINKS, an android-, web-based system. PLoS Negl Trop Dis (2014) 8:e2654. doi:10.1371/journal.pntd.0002654

25. Naik R, Tabana H, Doherty T, Zembe W, Jackson D. Client characteristics and acceptability of a home-based HIV counselling and testing intervention in rural South Africa. BMC Public Health (2012) 12:824. doi:10.1186/1471-2458-12-824

26. Maher D, Sekajugo J, Harries AD, Grosskurth H. Research needs for an improved primary care response to chronic non-communicable diseases in Africa. Trop Med Int Health (2010) 15:176-81. doi:10.1111/j.1365-3156.2009. 02438.x
27. Ojwang JK, Lee VC, Waruru A, Ssempijja V, Ng’ang’a JG, Wakhutu BE, et al. Using information and communications technology in a national population-based survey: the Kenya AIDS Indicator Survey 2012. J Acquir Immune Defic Syndr (2014) 66:S123-9. doi:10.1097/QAI.0000000000000116

28. Onono M, Carraher N, Cohen R, Bukusi E, Turan J. Use of personal digital assistants for data collection in a multi-site AIDS stigma study in rural south Nyanza, Kenya. Afr Health Sci (2011) 11:464-73.

29. Nahum LA, Reynolds MT, Wang ZO, Faith JJ, Jonna R, Jiang ZJ, et al. EGenBio: a data management system for evolutionary genomics and biodiversity. $B M C$ Bioinformatics (2006) 7:1-5. doi:10.1186/1471-2105-7-1

30. Phan V, Malasri K. BioTDMS: a general-purpose system for integrative management of bioinformatics tools and data. Int J Comput Biol Drug Des (2008) 1:174. doi:10.1504/IJCBDD.2008.020208

31. Jarlier F, Arleo A, Petit GH, Lefort JM, Fouquet C, Burguière E, et al. A navigation analysis tool (NAT) to assess spatial behavior in open-field and structured mazes. J Neurosci Methods (2013) 215:196-209. doi:10.1016/j. jneumeth.2013.02.018

32. Bakker R, Wachtler T, Diesmann M. CoCoMac 2.0 and the future of tract-tracing databases. Front Neuroinform (2012) 6:30. doi:10.3389/fninf.2012.00030

33. Herzberg S, Rahbar K, Stegger L, Schafers M, Dugas M. Concept and implementation of a single source information system in nuclear medicine for myocardial scintigraphy (SPECT-CT data). Appl Clin Inform (2010) 1:50-67. doi:10.4338/ACI-2009-12-RA-0017

34. Apple HealthKit. (2014). Available from: https://www.apple.com/ios/ios8/ health

35. Harris JK, Beatty KE, Lecy JD, Cyr JM, Shapiro RM II. Mapping the multidisciplinary field of public health services and systems research. Am J Prev Med (2011) 41:105-11. doi:10.1016/j.amepre.2011.03.015

36. Fadly El A, Daniel C, Bousquet C, Dart T, Lastic P, Degoulet P. Electronic healthcare record and clinical research in cardiovascular radiology. HL7 CDA and CDISC ODM interoperability. AMIA Annu Symp Proc (2007):216-20.

37. Kessel KA, Combs SE. Data management, documentation and analysis systems in radiation oncology: a multi-institutional survey. Radiat Oncol (2015) 10:41. doi:10.1186/s13014-015-0543-0

38. Reboussin D, Espeland MA. The science of web-based clinical trial management. Clin Trials (2005) 2:1-2. doi:10.1191/1740774505cn059ed

39. Schadt EE, Linderman MD, Sorenson J, Lee L, Nolan GP. Computational solutions to large-scale data management and analysis. Nat Rev Genet (2010) 11:647-57. doi:10.1038/nrg2857

Conflict of Interest Statement: The authors declare that the research was conducted in the absence of any commercial or financial relationships that could be construed as a potential conflict of interest.

Copyright $\odot 2016$ Kessel and Combs. This is an open-access article distributed under the terms of the Creative Commons Attribution License (CC BY). The use, distribution or reproduction in other forums is permitted, provided the original author(s) or licensor are credited and that the original publication in this journal is cited, in accordance with accepted academic practice. No use, distribution or reproduction is permitted which does not comply with these terms. 